\title{
УДК 666.3
}

Н. В. Жиренкина, М. А. Машковцев, Н. В. Обабков, И. Ф. Закиров

\section{Изучение влияния свойств исходных порошков $\mathrm{ZrO}_{2}-(7 \%) \mathrm{Y}_{2} \mathrm{O}_{3}$ на свойства керамических изделий}

Рассмотрена возможность формирования керамических изделий методом шликерного литья без стадии механического измельчения порошков. Исследовано влияние значения $\mathrm{pH}$ осаждения гидроксидов и проведения гидротермальной обработки на свойства порошков $\mathrm{ZrO}_{2}-(7 \%) \mathrm{Y}_{2} \mathrm{O}_{3}$, а также на механические свойства керамических изделий, изготовленных из синтезированных порошков $\mathrm{ZrO}_{2}-(7 \%) \mathrm{Y}_{2} \mathrm{O}_{3}$ без стадии помола. Показано, что на качество керамических изделий на основе оксида циркония в большей степени влияет удельная поверхность, а не размер частиц исходных порошков.

Ключевые слова: оксид циркония, порошки, осаждение, $p H$, удельная поверхность, керамические изделия, прочность на изгиб, шликерное литье.

\section{Введение}

Керамика на основе оксида циркония обладает рядом уникальных свойств, таких как низкая термопроводность, высокий коэффициент термического расширения, высокая термостабильность, высокая прочность, трещиностойкость, термоударная прочность [1], и используется в качестве термозащитных покрытий, биосовместимых материалов, коррозионностойких материалов, электропроводящей керамики [2]. При формировании керамических изделий на основе оксида циркония широко применяется метод шликерного литья [3]. Приготовление шликера включает стадию помола порошков, которая является энергои трудозатратной, приводит к загрязнению порошка мелющими телами и к его потере. Для приготовления шликера по стандартной технологии требуется измельчать полученные порошки в шаровых мельницах до размера порядка 3-5 мкм. Поэтому важно изучать синтез порошков на основе оксида циркония субмикронного размера для изготовления керамических изделий методом шликерного литья без стадии механического измельчения порошков. Широко распространено получение порошков субмикронного размера золь-гель технологией $[4,5]$, но результаты синтезов сильно разнятся, поэтому необходимо было воспроизвести патенты и изучить влияние процессов гидролиза на свойства порошков. Сложность изучения этой проблемы заключается в большом количестве параметров, влияющих на

(С) Жиренкина Н. В., Машковцев М. А., Обабков Н. В., Закиров И. Ф., 2019 свойства частиц и на небольшой размер зародышей, образующихся на первых минутах синтеза $[6,7]$. Оригинальность работы связана с изучением влияния таких параметров как значение $p H$ осаждения и введения сульфат-ионов. Целью работы являлось исследование влияния условий синтеза на свойства получаемых порошков и керамических образцов.

\section{Экспериментальная часть}

В качестве исходных соединений использовали карбонат циркония $\mathrm{ZrOCO}_{3}$ и оксид иттрия $\mathrm{Y}_{2} \mathrm{O}_{3}$. Соединения растворили в стехиометрическом количестве азотной кислоты, далее провели смешение приготовленных растворов в соотношении, необходимом для получения конечного продукта, содержащего $93 \%$ $\mathrm{ZrO}_{2}$ и $7 \% \mathrm{Y}_{2} \mathrm{O}_{3}$ по массе. Была определена оптимальная концентрация общего раствора после разбавления 150 г/л в пересчете на сумму оксидов.

Из раствора нитратов соответствующих металлов сформировали золь по технологии, детально описанной в патенте [5]: с помощью автоматической пипетки в раствор нитратов добавляли серную кислоту до достижения мольного соотношения $\mathrm{Zr}^{4+} / \mathrm{SO}_{4}^{2-}=1 / 0,5$, полученный раствор нагревали на электрической плитке с термодатчиком до $60{ }^{\circ} \mathrm{C}$. При этом образовывался золь белого цвета. Для стабилизации золь выдерживали при температуре $60{ }^{\circ} \mathrm{C}$ в течение 15 мин. В дальнейшем его использовали для осаждения гидратированных оксидов. В реактор при непрерывном перемешивании дозировали золь и водный раствор аммиака, постоянное значение $\mathrm{pH}$ в реакторе поддерживали равным 5 или 8 в зависимо- 
сти от образца путем регулирования скорости приливания водного раствора аммиака. После осаждения значение $p H$ реакционной среды по каплям доводили до 9 водным раствором аммиака. Затем часть образцов подвергали гидротермальной обработке в автоклаве при $130^{\circ} \mathrm{C}$. Все образцы сушили при температуре $120^{\circ} \mathrm{C}$ и обжигали при $800{ }^{\circ} \mathrm{C}$. Образцы, осажденные при $p H=5$ и $p H=8$, обозначены соответственно ZrY-5 и ZrY-8, а образцы с гидротермальной обработкой - ZrY-5go и ZrY-8go.

На следующем этапе готовили шликеры из полученных порошков без использования стадии механического измельчения. Для изготовления шликера брали 20 г порошка, 2 г волокна $\left(\mathrm{Al}_{2} \mathrm{O}_{3}-50-56 \%, \mathrm{ZrO}_{2}-14-17 \%\right.$, $\mathrm{SiO}_{2}-27-36 \%$, средний диаметр волокна 2-4 мкм), 40 г раствора $5 \%$ парафина в бензине, все реагенты смешивали в стеклянном стакане, и проводили отгонку бензина при температуре $130{ }^{\circ} \mathrm{C}$. Высушенную смесь засыпали в пресс-форму, нагретую до $60^{\circ} \mathrm{C}$, и прессовали при 5 МПа. Заготовки извлекали из пресс-формы, обжигали при $1200{ }^{\circ} \mathrm{C}$ в течение 1 ч, скорость нагрева заготовок составляла $4{ }^{\circ} \mathrm{C}$ в минуту. Из полученных заготовок вырезали образцы и проводили испытания на изгиб на разрывной машине [8].

Рентгенофазовый анализ образцов проводили на дифрактометре XPertPro MPD c твердотельным пиксельным детектором в излучении $\mathrm{Cu}_{\kappa \alpha}$ с использованием $\beta$-фильтра на вторичном пучке. ОКР (области когерентного рассеяния) определяли методом Шеррера по рефлексам в малых углах рассеяния (фактор формы $\mathrm{K}=0,9)$.

Электронные фотографии образцов материалов были получены при использовании электронного растрового микроскопа Carl
Zeiss SIGMA VP в режиме высокого вакуума с применением InLens детектора. Ускоряющее напряжение составляло 2 кВ.

Характеристики удельной поверхности и пористости образцов определяли с помощью метода низкотемпературной адсорбции/десорбции азота на приборе Quantachrome NOVA $1200 E$. Изотермы адсорбции/десорбции всех исследуемых образцов получали в следующем диапазоне относительных давлений: 0,1 ; 0,$2 ; 0,3 ; 0,4 ; 0,45 ; 0,5 ; 0,55 ; 0,6 ; 0,65 ; 0,7 ; 0,75$; 0,$8 ; 0,85 ; 0,9 ; 0,95 ; 0,98$ и 0,99 . Время предварительной дегазации образцов составляло 1 ч.

Гранулометрический состав порошков определяли методом лазерной дифракции на приборе ANALYSETTE 22 NanoTec plus компании FRITSCH. Измерение проводилось в водной среде, для дополнительного диспергирования частиц в процессе измерения использовали ультразвуковой генератор.

Плотность образцов определяли путем замера массы и геометрических размеров. Для определения открытой пористости проводили гидростатическое взвешивание образцов в воде.

\section{Результаты и обсуждение}

Рентгенофазовый анализ показал, что все синтезированные порошки являются твердыми растворами замещения тетрагональной структуры с эмпирической формулой, близкой к $\mathrm{Y}_{0,08} \mathrm{Zr}_{0,92} \mathrm{O}_{2}$, отличающимися только размерами областей когерентного рассеивания (ОКР). Для образцов ZrY-8 и ZrY-8go обнаружены следовые количества 7 \% моноклинной фазы, в табл. 1 приведены размеры ОКР тетрагональной фазы для всех образцов. Для образца $\mathrm{ZrY}-8 g o$ характерен наименьший размер ОКР. Гидротермальная обработка приводит к уменьшению размеров ОКР, возможно, вследствие

Таблица 1

Свойства порошков $\mathrm{ZrO}_{2}-(7 \%) \mathrm{Y}_{2} \mathrm{O}_{3}$

\begin{tabular}{|c|c|c|c|c|c|}
\hline \multirow{2}{*}{ Образец } & \multicolumn{5}{|c|}{ Порошки } \\
\cline { 2 - 6 } & ОКР, $\AA$ & $\begin{array}{c}\text { Средний размер } \\
\text { частиц, } D_{\text {ср }, \text { мкм }}\end{array}$ & $\begin{array}{c}\text { Удельная } \\
\text { поверхность, }{ }^{2} / \Gamma\end{array}$ & $\begin{array}{c}\text { Общая } \\
\text { пористость, мл/г }\end{array}$ & $\begin{array}{c}\text { Средний диаметр } \\
\text { пор } D_{\text {ср }}, \AA\end{array}$ \\
\hline ZrY-8go & 120 & 22,20 & 73,0 & 0,387 & 212 \\
\hline ZrY-8 & 185 & 15,40 & 38,5 & 0,268 & 278 \\
\hline ZrY-5go & 230 & 3,16 & 44,4 & 0,082 & 73 \\
\hline ZrY-5 & 260 & 3,10 & 24,6 & 0,051 & 84 \\
\hline
\end{tabular}




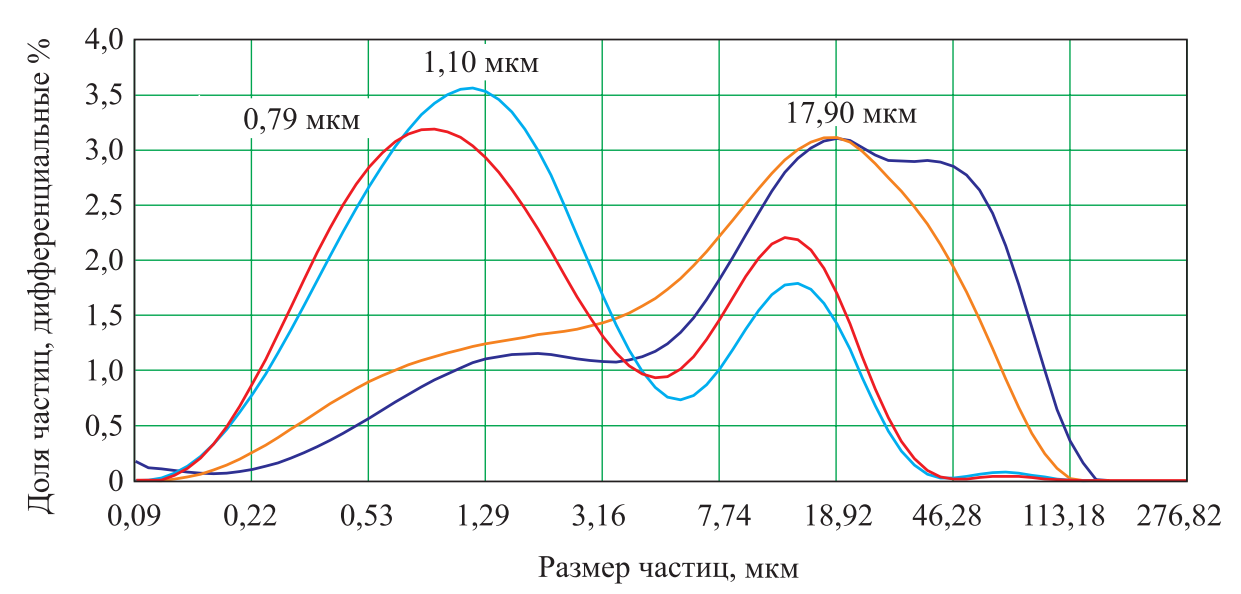

Рис. 1. Распределение частиц по размеру:

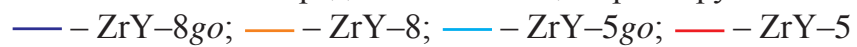

увеличения дефектности и пористости на границе кристаллитов.

Гранулометрический состав порошков показан на рис. 1. В табл. 1 приведен средний размер частиц $\left(D_{\mathrm{cp}}\right)$. Для всех образцов характерно бимодальное распределение частиц по размеру с первым пиком в области 1 мкм и со вторым пиком в области 10-18 мкм. Наименьшим средним диаметров обладают образцы, осажденные при $p H=5$, что может быть связано с наличием поблизости изоэлектрической точки оксида циркония. Установлено, что гидротермальная обработка несущественно влияет на распределение частиц образцов по размерам. Наибольший средний диаметр частиц имеет образец $\mathrm{ZrY}-8 g o$.
На рис. 2 представлены изотермы адсорбции и десорбции азота для всех образцов. По виду петель гистерезиса на изотермах можно определить форму пор. Для полученных образцов характерны поры цилиндрической формы, однако в образце ZrY-5 присутствуют щелевидные поры [9]. Параметры поверхности и пористости образцов приведены в табл. 1. Образец ZrY-8go имеет наибольшую удельную поверхность, пористость и диаметр пор. Вероятно, $p H$ осаждения наиболее сильно влияет на размеры ОКР и параметры пористости: осаждение при высоком значении $\mathrm{pH}$ обусловливает высокую степень пересыщения в месте падении капли, а также высокую специфичную адсорбцию гидроксил-ионов на поверхно-

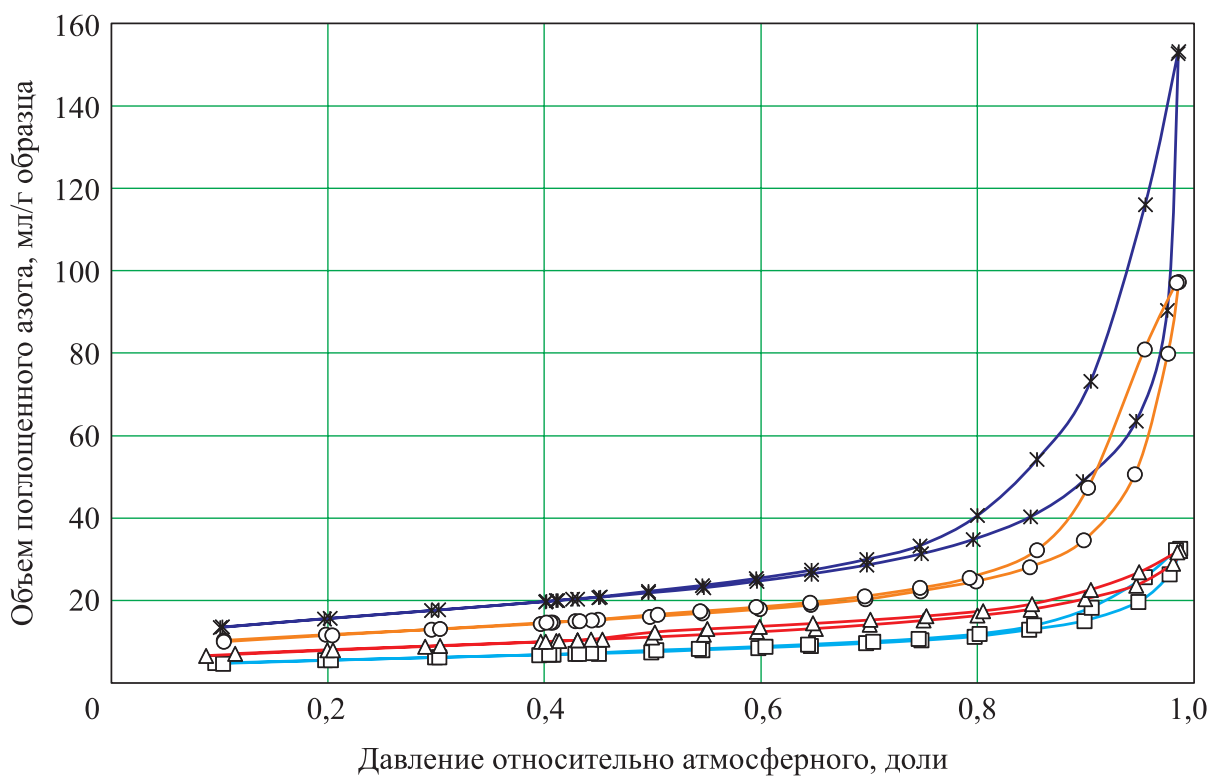

Рис. 2. Изотермы адсорбции/десорбции образцов: $\rightarrow-\mathrm{ZrY}-8 g o ;-\circ-\mathrm{ZrY}-8$; - - - ZrY-5go; $---\mathrm{ZrY}-5$ 
сти образующихся частиц, что предотвращает процессы рекристаллизации частиц гидратированных оксидов в процессе осаждения и гидротермальной обработки и приводит к формированию частиц с низким размером ОКР и с высокоразвитой пористостью. Осаждение при $p H=5$ обусловливает снижение степени пересыщения в месте падения капли, а также уменьшение специфической адсорбции гидроксил-ионов, что приводит к интенсификации процессов рекристаллизационного роста частиц в процессе осаждения и к конечному увеличению размеров ОКР.

На рис. 3 приведены электронные фотографии образцов ZrY-5go и ZrY-5. На фотографиях видно, что оба образца представляют собой слабосвязанные агрегаты, состоящие из частиц, имеющих близкую к сферической форму и размер порядка 25 нм, что согласуется со

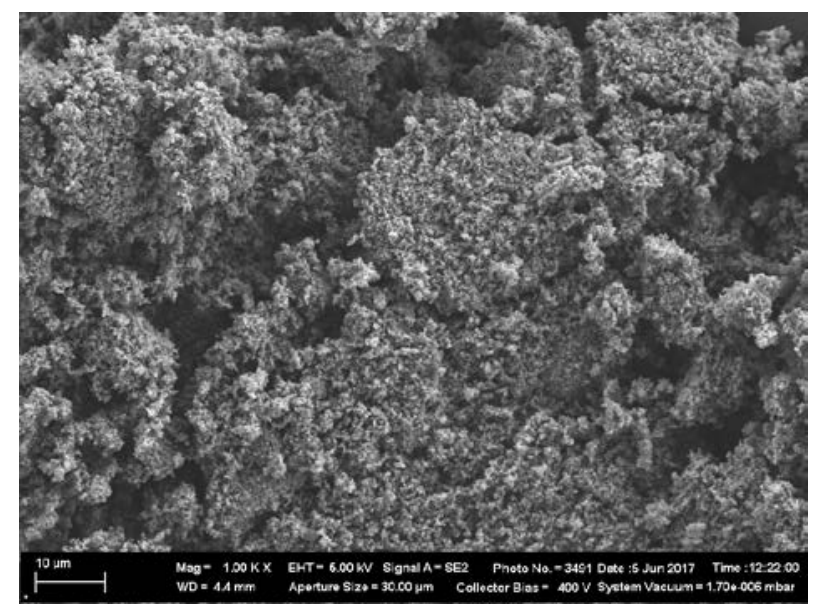

a

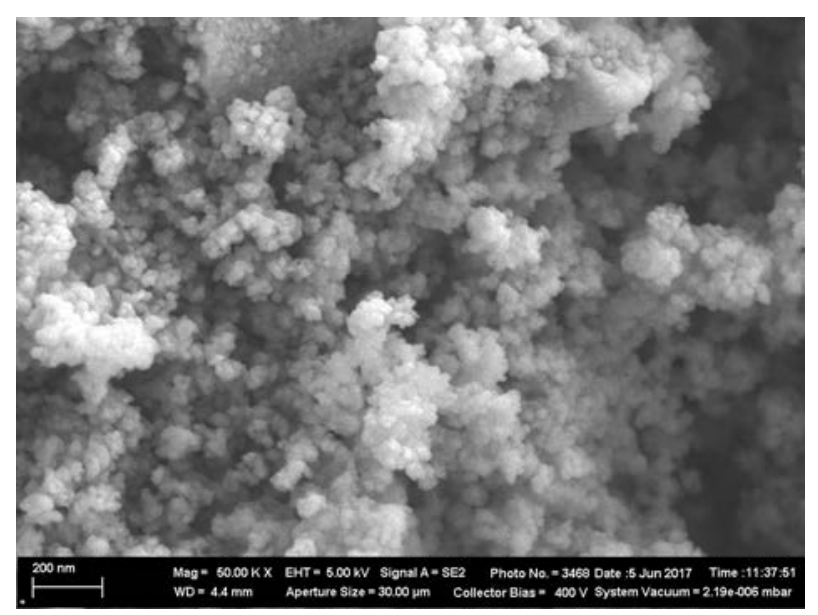

B значением размеров ОКР, полученных из данных рентгенофазового анализа. Для образца ZrY-5go характерна меньшая плотность агрегирования первичных частиц, что согласуется с большим значением удельной поверхности и пористости этого образца по сравнению с образцом ZrY-5. Вероятно, введение стадии гидротермальной обработки приводит к снижению избыточной поверхностной энергии за счет процессов плавной дегидратации и рекристаллизации.

На рис. 4 представлены электронные фотографии образцов ZrY-8go и ZrY-8. Для образца ZrY-8go наблюдаются агрегаты осколочной формы, которые состоят из первичных частиц, частицы имеют достаточно плотную упаковку и их размер существенно ниже, чем у предыдущих образцов, что согласуется со значением размера ОКР $120 \AA$, полученным

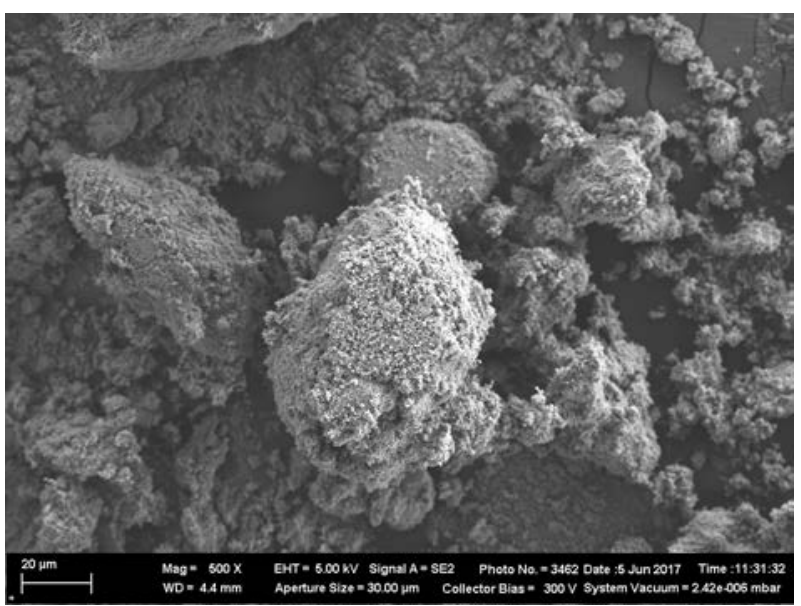

6

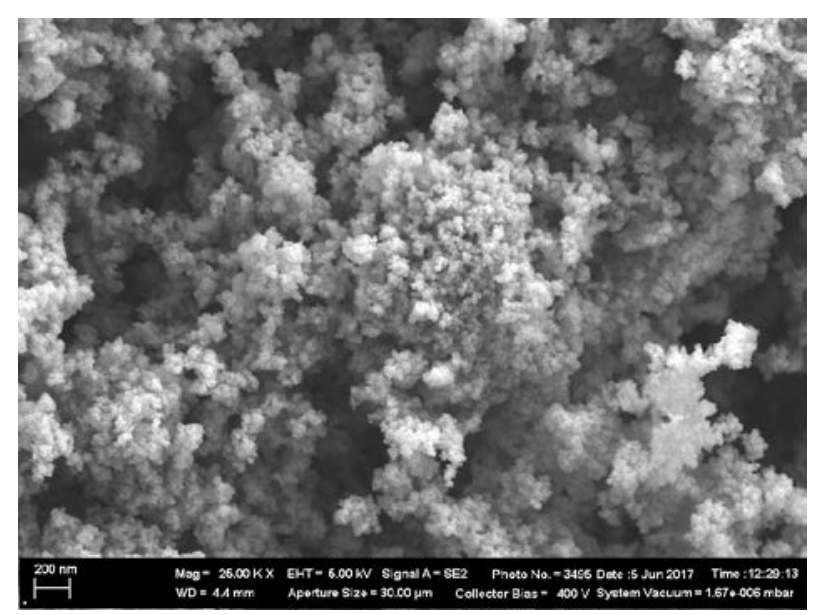

$\Gamma$

Рис. 3. Электронные фотографии образцов: a, г-ZrY-5go; б, в - ZrY-5 


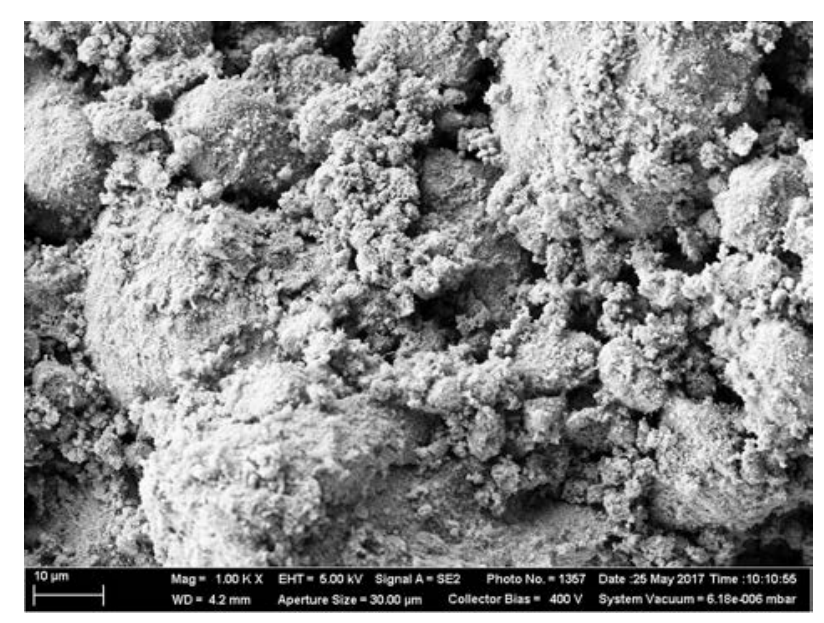

a

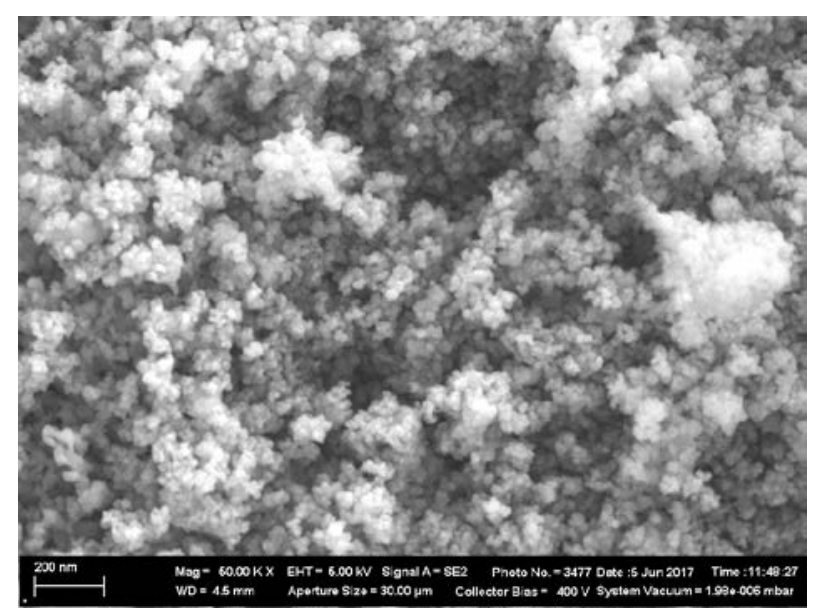

B

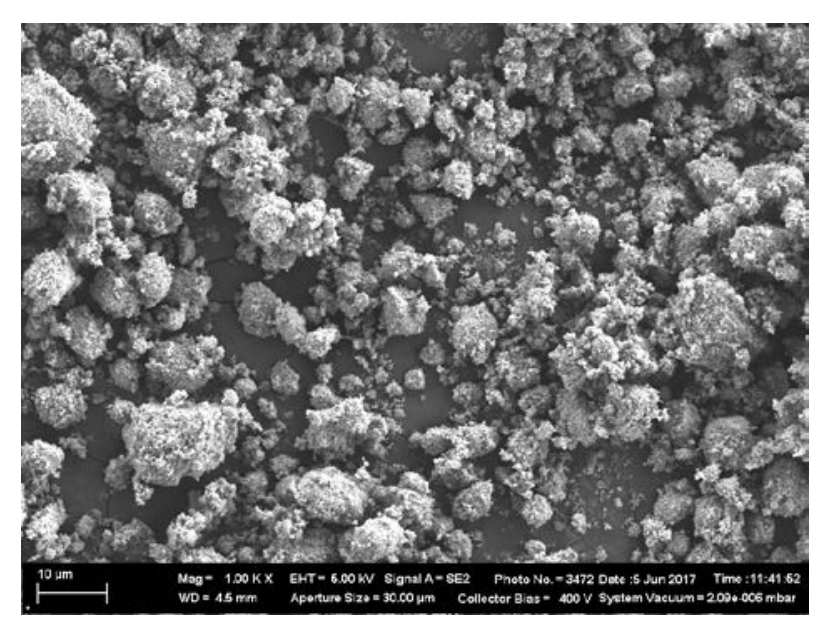

6

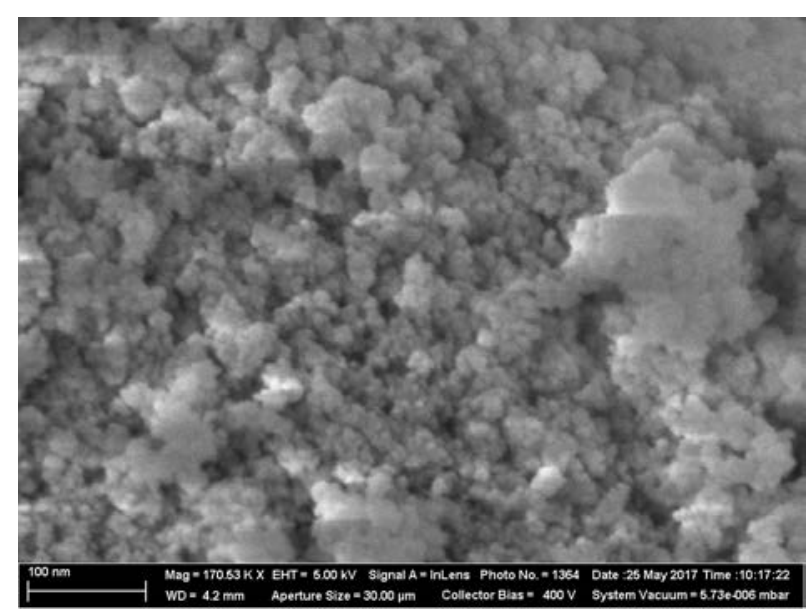

$\Gamma$

Рис. 4. Электронные фотографии образцов: a, г-ZrY-8go; б, в - ZrY-8

из данных рентгенофазового анализа. Образец обладает наибольшей удельной поверхностью и наименьшим размером ОКР, что провоцирует сильное агрегирование частиц. На рис. 4 показано, что размер первичных частиц у образца ZrY-8 больше, чем у образца с гидротермальной обработкой, что согласуется с данными рентгенофазового анализа.

Параметры композитов, полученных из синтезированных порошков, приведены в табл. 2. Керамическое изделие из образца $\mathrm{ZrY}-8$ развалилось, и не удалось измерить его свойства, предположительно, ввиду большого размера частиц, относительно низкой удельной поверхности, достаточно высокой пористости. Керамический образец в процессе обжига, не обладая развитой поверхностью, недостаточно сильно связался между собой, претерпел сильную усадку, вероятно, вследствие этого он распался. Для всех исследованных керамических образцов характерны низкие значения предела прочности на изгиб по сравнению с образцами, получаемыми по традиционной технологии. Вероятно, что в процессе помола осуществляется не только механическое измельчение, но и механохимическая активация поверхности образцов, за счет чего происходит лучшее спекание. Так, композит ZrY-8go характеризуется самой высокой плотностью и

Таблица 2

Свойства керамических изделий

\begin{tabular}{|c|c|c|c|}
\hline \multirow{2}{*}{ Образец } & \multicolumn{3}{|c|}{ Керамические изделия } \\
\cline { 2 - 4 } & $\begin{array}{c}\text { Плотность, } \\
\text { Г/см }\end{array}$ & $\begin{array}{c}\text { Открытая } \\
\text { пористость, \% }\end{array}$ & $\begin{array}{c}\text { Предел прочности } \\
\text { на изгиб, МПа }\end{array}$ \\
\hline ZrY-8go & 3,3 & 35,2 & 18 \\
\hline ZrY-5go & 2,9 & 34,3 & 13 \\
\hline ZrY-5 & 2,3 & 38,8 & 5 \\
\hline
\end{tabular}


пределом прочности на изгиб на уровне только 18 МПа. Вероятно, за счет высокой пористости и удельной поверхности порошка частицы эффективно спекаются даже без дополнительной механохимической активации.

У композитов ZrY-5 и ZrY-5go все механические характеристики ниже, чем у композита ZrY-8go, причем наблюдается тенденция роста плотности и предела прочности композитов с ростом удельной поверхности исходных порошковых материалов и снижением размера ОКР. Возможно, введение операции предварительного диспергирования порошков стабилизированного иттрием диоксида циркония в бисерной или коллоидной мельнице приведет к существенному улучшению механических свойств композитов, получаемых при использовании технологии шликерного литья.

\section{Заключение}

В работе проведен синтез порошков $\mathrm{ZrO}_{2}-$ (7 \%) $\mathrm{Y}_{2} \mathrm{O}_{3}$ в различных условиях. Удалось синтезировать высокодисперсные порошки без дополнительного измельчения с пиком распределения частиц размером менее 1 мкм. Из полученных порошков без помола синтезированы керамические композиты методом шликерного литья, исследованы свойства порошков и спеченных изделий. Выявлено, что склонность порошков к спеканию в первую очередь определяют их удельная поверхность и пористость, а не размер частиц исходных порошков. Для улучшения механических свойств композитов необходимо ввести стадию дополнительной механохимической активации поверхности порошков.

\section{Список литературы}

1. Navin Ch., Deepesh K. S., Meenakshi Sh. et. al. Synthesis and characterization of nano-sized zirconia powder synthesized by single emulsion-assisted direct precipitation // Journal of
Colloid and Interface Science. 2010. No. 342. Pp. 327-332.

2. Khorramie S. A., Baghchesara M. A., Lotfil Sh., Moradi D. et. al. Synthesis of $\mathrm{ZrO}_{2}$ nanoparticle by combination of sol-gel auto-combustion method- irradiation technique, and preparation of $\mathrm{Al}-\mathrm{ZrO}_{2}$ metal matrix composites // International Journal of Nano Dimension. 2012. No. 4. Pp. 261-267.

3. А. П. Гаршин, В. М. Гропянов, Г. П. Зайцев и др. Керамика для машиностроения. М.: Научтехлитиздат, 2003. С. 121-131.

4. Manufacturing method for zirconia/ceria-based composite oxide: pat. JP2003137550 / I. T. Yasuhide, N. Colin, E. Gavin, Ch. Ian. Published 14.05.2003. 8 p.

5. Zirconium oxide, precursor of the same and method for producing them: pat. JP2010143813 / I. I. Naoki, S. Mineo, K. Kazuyuk, S. Yasuhiro. Published 01.07.2010. 12 p.

6. Zhirenkina N. V., Mashkovtsev M. A., Obabkov $N$. $V$. et. al. The effect of addition of $\mathrm{SO}_{4}$ 2-ions on the properties of $\mathrm{ZrO}_{2}-(7 \%) \mathrm{Y}_{2} \mathrm{O}_{3}$ powders obtained by hydroxide precipitation // AIP Conference Proceedings. 2018. № 1886. C. 020047-1-020047-5.

7. Zhirenkina N. V., Mashkovtsev M. A., Bereskina $P$. A. et. al. The effect of preliminary hydrolysis on the properties of $\mathrm{ZrO}_{2}-(7 \%) \mathrm{Y}_{2} \mathrm{O}_{3}$ powders prepared by hydroxide precipitation // AIP Conference Proceedings. 2017. № 2015. C. 020125-1-020125-6.

8. ГОСТ Р 56805-2015. Композиты полимерные. Методы определения механических характеристик при изгибе. М.: Стандартинформ, 2016. 15 c.

9. Broekhoff J. C. P. Mesopore determination from nitrogen sorption isotherms: Fundamentals, scope, limitations // Studies in surface science and catalysis. 1979. Vol. 3. Pp. 663-684.

\section{Поступила 21.03.18}

\footnotetext{
Жиренкина Нина Валерьевна - аспирант федерального государственного автономного профессионального учреждения высшего профессионального образования «Уральский федеральный университет имени первого Президента России Б. Н. Ельцина, Физико-технологический институт» кафедры «Редкие металлы и наноматериалы», г. Екатеринбург.

Область научных интересов: оксидные керамические материалы и наноматериалы.
} 
Машковцев Максим Алексеевич - кандидат химических наук, доцент федерального государственного автономного профессионального учреждения высшего профессионального образования «Уральский федеральный университет имени первого Президента России Б. Н. Ельцина, Физико-технологический институт» кафедры «Редкие металлы и наноматериалы», г. Екатеринбург.

Область научных интересов: оксидные керамические материалы и наноматериалы.

Обабков Николай Васильевич - доктор технических наук, доцент, профессор федерального государственного автономного профессионального учреждения высшего профессионального образования «Уральский федеральный университет имени первого Президента России Б. Н. Ельцина, Физико-технологический институт» кафедры «Редкие металлы и наноматериалы», г. Екатеринбург.

Область научных интересов: оксидные керамические материалы и наноматериалы.

Закиров Ильсур Фларитович - инженер 2-й категории кафедры «Редкие металлы и наноматериалы» Федерального государственного автономного образовательного учреждения высшего образования «Уральский федеральный университет имени первого Президента России Б. Н. Ельцина», г. Екатеринбург.

Область научных интересов: высокотемпературная керамика и композиционные материалы.

\section{Studying the influence of properties of initial $\mathrm{ZrO}_{2}-(7 \%) \mathrm{Y}_{2} \mathrm{O}_{3}$ powders on properties of ceramic products}

The paper focuses on the possibility of forming ceramic products by the method of slip casting without the stage of mechanical grinding of powders. We studied the influence of $\mathrm{pH}$ value of hydroxides precipitation and hydrothermal treatment on the properties of $\mathrm{ZrO}_{2}-(7 \%) \mathrm{Y}_{2} \mathrm{O}_{3}$ powders, and on the mechanical properties of ceramic products made from synthesized $\mathrm{ZrO}_{2}-(7 \%) \mathrm{Y}_{2} \mathrm{O}_{3}$ powders without a grinding stage. Findings of research show that the quality of ceramic products based on zirconium oxide is more influenced by the specific surface area, rather than the particle size of the initial powders.

Keywords: zirconium oxide, powders, precipitation, $\mathrm{pH}$, specific surface, ceramic products, bending strength, slip casting.

Zhirenkina Nina Valer'evna - post-graduate student, Federal State Autonomous Educational Institution of Higher Professional Education "Ural Federal University named after the first President of Russia B. N. Yeltsin", Institute of Physics and Technology, Department of Rare Metals and Nanomaterials, Ekaterinburg.

Science research interests: oxide ceramic materials and nanomaterials.

Mashkovtsev Maksim Alekseevich - Candidate of Chemical Sciences, Associate Professor, Federal State Autonomous Educational Institution of Higher Professional Education "Ural Federal University named after the first President of Russia B. N. Yeltsin", Institute of Physics and Technology, Department of Rare Metals and Nanomaterials, Ekaterinburg.

Science research interests: oxide ceramic materials and nanomaterials.

Obabkov Nikolay Vasil'evich - Doctor of Engineering Sciences, Associate Professor, Professor, Federal State Autonomous Educational Institution of Higher Professional Education "Ural Federal University named after the first President of Russia B. N. Yeltsin”, Institute of Physics and Technology, Department of Rare Metals and Nanomaterials, Ekaterinburg.

Science research interests: oxide ceramic materials and nanomaterials.

Zakirov Ilsur Flaritovich - second category engineer, Department of Rare Metals and Nanomaterials, Federal State Autonomous Educational Institution of Higher Education "Ural Federal University named after the First President of Russia B. N. Yeltsin", Ekaterinburg.

Science research interests: high-temperature ceramics and composite materials. 